\title{
Assessment of Knowledge and Practices of Mothers on the Home Management of Diarrhea in the Northern Part of Cameroon
}

\author{
Andreas Chiabi ${ }^{1 *}$, Félicitée D Nguefack ${ }^{1}$, Palma H Abouame ${ }^{2}$, Seraphin Nguefack $^{1}$, Nelson S. Njedock ${ }^{1}$, Edmond N \\ Chiabi $^{2}$, Roland M Chiabi ${ }^{2}$ and Marie T Obama ${ }^{2}$ \\ ${ }^{1}$ Faculty of Medicine and Biomedical Sciences, University of Yaounde I, Cameroon / Yaounde Gynaeco-Obstetric and Pediatric Hospital, \\ Cameroon
}

${ }^{2}$ Faculty of Medicine and Biomedical Sciences, University of Yaounde I, Cameroon

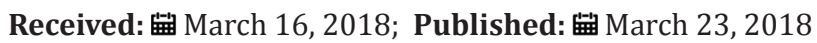

*Corresponding author: Andreas Chiabi, Pediatric Unit, Yaounde Gynaeco-Obstetric and Pediatric Hospital / Faculty of Medicine and Biomedical Sciences, University of Yaounde I, P.O. Box 4362, Yaounde, Cameroon

\begin{abstract}
Knowledge and practices of mothers on the home management of diarrhea is a key element in the management of diarrhea in a child so as to intervene early and thereby avoiding complications. The knowledge and practices of mothers on the early management of diarrhea at home is important in the prevention of diarrhea related complications. Despite all the strategies put in place in communities and health facilities to reduce childhood mortality in Cameroon, the prevalence of diarrheal diseases remains high, especially in the northern regions. This study was aimed at assessing the knowledge and practices of mothers on the home management of childhood diarrhea in Ngaoundere, a town in the northern part of Cameroon where its prevalence still remains high. This was a cross sectional and analytical study in the urban zone of the Ngaoundere from February $1^{\text {st }}$ to April $30^{\text {th }} 2015$. Five-hundred-and-fifty mothers participated in the study. A score was established to rate the variables "knowledge" and "practices" of mothers. Data were collected and entered in a questionnaire. Analysis was done with SPSS version 20.0. The threshold of significance was defined as a P-value less than 0.05.

The majority (40.7\%) of mothers were aged between 15 and 25 years. Most of them (40.4\%) had reached secondary school level while $68.5 \%$ were housewives with $76.1 \%$ having adequate knowledge on diarrhea and good home management. The mothers' and fathers' level of education significantly ( $\mathrm{P}=0.02$ and 0.000 respectively) influenced the mothers' knowledge. Good practices were performed by $66.3 \%$ of the mothers. The factors that influenced these good practices were: the academic level and profession of the parents $(\mathrm{P}<0.01)$, the household environment namely the use of taps and the presence of latrine toilets $(\mathrm{P}=0.013)$. Most mothers have sufficient knowledge as well as good practices towards the home management of diarrhea. These are influenced by the level of education and profession of the parents, health education and by the environment the family lives in.
\end{abstract}

Keywords: Children; Mothers; Diarrhea; Cameroon

Abbreviations: IMCI: Integrated Management of Childhood Illness; ORS: Oral rehydration salts; ORT: Oral Rehydration Therapy; UNICEF: United Nations Children's Fund; WHO: World Health Organization

\section{Introduction}

Acute diarrhea is defined as the emission of at least three watery stools per day or the emission of stools more frequently than usual by an individual [1]. It is the second cause of childhood mortality after pneumonia with 1.5 million deaths per year [1]. Diarrhea is a major public health issue in developing countries. It accounts for one of the major causes of infant morbidity and mortality, as a result of the severe consequences which are essentially due to acute dehydration and malnutrition [2]. Oral rehydration salts (ORS) and Oral rehydration therapy (ORT), adopted by the United Nations Children's Fund (UNICEF) and the World Health Organization 
(WHO) in the late 1970s led to better management of cases of childhood diarrhea [3].

In Cameroon, despite the existence of effective and available measures, the management of diarrhea remains a major problem in our context as demonstrated in the last 2011 demographic survey in which $21 \%$ of children had diarrhea, with only $23 \%$ seeking medical treatment from a health facility. Furthermore, only $17 \%$ and $22 \%$ of the sick children received ORT [4]. Thus the knowledge and practices of mothers with regards to diarrhea at home remains a crucial point in the management so as to intervene early on the first signs and avoid complications. That is why we proposed to evaluate the knowledge and practices of mothers in the management of diarrhea in children under 5 in the town of Ngaoundere, in the northern region of Cameroon.

\section{Materials and Methods}

\section{Study design and setting}

It was a cross-sectional and analytical study done from February $1^{\text {st }}$ to April $30^{\text {th }} 2015$ in the urban area of Ngaoundere. Ngaoundere is the capital town of the Adamawa region in the northern part of Cameroon. It has a population of 224,215 inhabitants of which 37,892 are children less than 5 years, and 54,484 women at child bearing age [5].

\section{Sampling and data collection}

We used a pretested questionnaire. For those who could not read or write, interpreters translated the questionnaire into the local dialect. Participation in the survey was voluntary and anonymity preserved. Informed consent was obtained from the parents before inclusion in the study.

Choice of quarters: To have a representative population, four quarters were drawn at random per health area from the total number of quarters in the area provided they were easy to access.

Choice of homes: We applied the method use by WHO for community surveys [6]. We visited the homes identified during the recent vaccination campaigns; these were the homes with children under five. The starting point in each quarter was the chiefdom. We randomly selected a direction with the use of a coin (heads or tails). Then we advanced in one direction until we reached the total number of households. When the total number was not obtained, we continued in the opposite direction. The number of mothers interviewed was evenly distributed in all the quarters chosen.

\section{Selection criteria}

We included the mothers of children aged less than 5years who had had at least one episode of diarrhea in the past and who were living in the town. Mothers and guardians with no permanent residence in the area were not included.

\section{Variables studied}

Demographic data: maternal age, marital status, educational level and occupation of the mothers and fathers.
Environmental factors: size of the household, access to drinking water, and use of latrines.To evaluate the knowledge and practices of the mothers, we used cutoff scores established in studies done in Iran in 2013 by Ghasemi et al. [7] and Khalili et al. [8]. The knowledge score was assessed using a 6-item questionnaire (sources of information on diarrhea, health education on diarrhea, definition of diarrhea, definition of dysentery, knowledge of the causes and consequences of diarrhea, knowledge of ORS and zinc and knowledge of preventive measures. The total score was 24 points (see annex). As for the practices of the mothers, they were asked to describe the home management of diarrhea. A9item questionnaire was used for this purpose (the treatment they administered, administration of ORS and zinc, other treatments administered to the child, feeding during diarrhea, and symptoms that prompted consultation, and the person consulted) with a total of 9 points (see Appendix).

The scoring was 1 point for a correct answer and 0 point for a wrong answer. The mean score was obtained by dividing the total score by 2 . Every right answer received the score of 1 , and every wrong answer got zero. The women could get a score between zero and 22 . The scores below 11, between 11 and 17, and more than 18 were considered, low, medium and good knowledge respectively. Mothers scoring above average were considered to have adequate knowledge and good practices. Mothers with a score below average were considered as having poor knowledge and poor practices. The mothers' environment involved two items namely the presence of latrine and the use of home tap water.

\section{Data analysis}

Data were entered in to CS-Pro 4.1 and analyzed using SPSS 20.0 software. The Chi-squared test was performed to examine associations between the variables, knowledge, practices of mothers with sociodemographic and environmental factors. A P value of 0.05 was used to determine the threshold of significance.

\section{Results}

We interviewed 540 mothers of children below 5years. The majority of mothers (40.7\%) were 15-25 years old. We noted that $40.7 \%$ of them attended secondary school and $23.7 \%$ were uneducated. Most of them were housewives (68.5\%) and lived with a partner (84\%). The majority of the fathers $(42.4 \%)$ had reached secondary school level and (62.4\%), were doing liberal professions. More than $55 \%$ of the mothers lived in households that used tap water and latrine, majority (76.1\%) of which had sufficient knowledge about diarrhea. Health facilities were the most cited source of information by $85.7 \%$ of the mothers. Most of them (37.8\%) knew the definition of diarrhea as the emission of more than 3 liquid stools per day. Most (91.7\%) cited inadequate food hygiene as a cause of diarrhea and proper food hygiene as a means of prevention (93\%).

The factors that influenced significantly the knowledge of mothers on diarrhea were the level of education of the mothers (P 
$=0.026)$, and the level of education of the fathers $(\mathrm{P}=0.000)$ (Table 1). This knowledge increased as parental education increased. We found a statistically significant relationship between the profession of the mothers and their knowledge. Mothers who were civil servants had better knowledge than the others $(\mathrm{P}=0.014)$ (Table $2)$. The father's occupation had a significant influence on the knowledge of the mothers $(\mathrm{P}=0.012)$. Mothers whose husbands were civil servants had a better knowledge. Health talks significantly influenced the knowledge of mothers ( $\mathrm{P}=0.03)$, and mothers who had received health talks had better knowledge on diarrhea (Table 3 ). Living in households with tap water and latrines also, appeared to be significantly associated with a better knowledge for the mothers $(\mathrm{P}=0.000)$ (Table 4).

Most mothers had good practices with regards to diarrhea $(66.3 \%)$. The vast majority $(90 \%)$ consulted a health facility anytime they had a case of diarrhea, and $67.2 \%$ and $31.3 \%$ reported using oral rehydration salts, and zinc respectively. As for food, $90.7 \%$ of mothers continued to feed the child during the diarrheal episode and $91.7 \%$ kept on breastfeeding. Mothers' practices were significantly improved with the level of parental education $(\mathrm{P}=$ 0.006 ) and with their profession (Table 5). Best practices were observed in mothers in the civil service $(\mathrm{P}=0.002)$ and in those whose husbands were civil servants $(P=0,007)$. Mothers who received health education had better practices $(\mathrm{P}=0.000)$ (Table $6)$. The availability of tap water and latrines had a positive effect on maternal practices $(\mathrm{P}=0.013)$ (Table 7).

Table 1: Relation between parents' level of education and knowledge of mothers.

\begin{tabular}{|c|c|c|c|}
\hline $\begin{array}{l}\text { Parents' Level } \\
\text { of education }\end{array}$ & $\begin{array}{c}\text { Insufficient } \\
\text { Knowledge n (\%) }\end{array}$ & $\begin{array}{c}\text { Sufficient } \\
\text { knowledge } \mathrm{n}(\%)\end{array}$ & P-value \\
\hline \multicolumn{4}{|c|}{ Mothers' level of education } \\
\hline Illiterate & $42(32,9)$ & $86(67,1)$ & \multirow{4}{*}{0.026} \\
\hline Primary & $38(22,9)$ & $128(77,1)$ & \\
\hline Secondary & $46(21,2)$ & $172(78,8)$ & \\
\hline $\begin{array}{l}\text { Higher } \\
\text { education }\end{array}$ & $3(10,8)$ & $25(89,2)$ & \\
\hline \multicolumn{4}{|c|}{ Fathers' Level of education } \\
\hline Illiterate & $37(47,5)$ & $41(52,5)$ & 0.000 \\
\hline Primary & $44(29,2)$ & $107(70,8)$ & \\
\hline Secondary & $38(16,6)$ & $191(83,4)$ & \\
\hline $\begin{array}{l}\text { Higher } \\
\text { education }\end{array}$ & $10(12,2)$ & $72(87,8)$ & \\
\hline
\end{tabular}

Table 2: Relationship between parental occupation and knowledge of mothers.

\begin{tabular}{|c|c|c|c|}
\hline $\begin{array}{c}\text { Profession of } \\
\text { the parents }\end{array}$ & $\begin{array}{c}\text { Insufficient } \\
\text { knowledgen (\%) }\end{array}$ & $\begin{array}{c}\text { Sufficient } \\
\text { knowledge n (\%) }\end{array}$ & P-value \\
\hline \multicolumn{4}{|c|}{ Profession of the mothers } \\
\hline Housewives & $97(27)$ & $273(73)$ & 0.014 \\
\hline $\begin{array}{c}\text { Liberal } \\
\text { profession } *\end{array}$ & $25(27)$ & $69(73)$ & \\
\hline
\end{tabular}

\begin{tabular}{|c|c|c|c|}
\hline $\begin{array}{l}\text { Non liberal } \\
\text { profession } * *\end{array}$ & $6(11)$ & $52(89)$ & \\
\hline Student / pupil & $1(6)$ & $17(94)$ & \\
\hline \multicolumn{4}{|c|}{ Profession of the fathers } \\
\hline None & $8(32)$ & $17(68)$ & \multirow{4}{*}{0.012} \\
\hline $\begin{array}{l}\text { Liberal } \\
\text { profession }\end{array}$ & $94(27)$ & $246(73)$ & \\
\hline $\begin{array}{l}\text { Non liberal } \\
\text { profession }\end{array}$ & $23(14,7)$ & $134(85,3)$ & \\
\hline Student/pupil & $4(23)$ & $14(77)$ & \\
\hline
\end{tabular}

* Any profession exercised on the basis of well-defined qualifications, by an individual, independently and under the person's own responsibility [15].

** Professions exercised under the responsibility of a third party. Referring to civil servants in our study [15]

Table 3: Relationship between health education and knowledge of mothers.

\begin{tabular}{|c|c|c|c|}
\hline & $\begin{array}{c}\text { Insufficient } \\
\text { Knowledge n (\%) }\end{array}$ & $\begin{array}{c}\text { Sufficient } \\
\text { knowledge n (\%) }\end{array}$ & P-value \\
\hline \multicolumn{4}{|c|}{ Educational talks } \\
\hline Received & $45(19)$ & $188(81)$ & 0.03 \\
\hline Not received & $84(27)$ & $223(73)$ & \\
\hline
\end{tabular}

Table 4: Relation between mothers and their knowledge of the environment.

\begin{tabular}{|c|c|c|c|}
\hline & $\begin{array}{c}\text { Insufficient } \\
\text { Knowledge n (\%) }\end{array}$ & $\begin{array}{c}\text { Sufficient } \\
\text { knowledge n (\%) }\end{array}$ & \multirow{2}{*}{ P-value } \\
\hline \multicolumn{4}{|c|}{ Environment } \\
\cline { 1 - 2 } Unfavorable & $74(62)$ & $156(38)$ & \multirow{2}{*}{0.000} \\
\hline Favorable & $55(38)$ & $255(62)$ & \\
\hline
\end{tabular}

Table 5: Relationship between the level of education, parental occupation and practices of mothers.

\begin{tabular}{|c|c|c|c|}
\hline & $\begin{array}{c}\text { Poor } \\
\text { practicesn }(\%)\end{array}$ & $\begin{array}{c}\text { Good } \\
\text { practicesn (\%) }\end{array}$ & $P$-value \\
\hline \multicolumn{4}{|c|}{ Mothers' level of education } \\
\hline Uneducated & $54(42)$ & $74(58)$ & \multirow{4}{*}{0.006} \\
\hline Primary & $62(37)$ & $104(63)$ & \\
\hline Secondary & $62(28)$ & $156(72)$ & \\
\hline $\begin{array}{c}\text { Higher } \\
\text { education }\end{array}$ & $4(14)$ & $24(86)$ & \\
\hline \multicolumn{4}{|c|}{ Level of education of father } \\
\hline Uneducated & $35(45)$ & $43(55)$ & \multirow{4}{*}{0.006} \\
\hline Primary & $56(37)$ & $95(63)$ & \\
\hline Secondary & $75(33)$ & $154(67)$ & \\
\hline $\begin{array}{c}\text { Higher } \\
\text { education }\end{array}$ & $16(20)$ & $66(80)$ & \\
\hline \multicolumn{4}{|c|}{ Mothers' occupation } \\
\hline Students /pupil & $6(33)$ & $12(67)$ & \multirow{2}{*}{0.002} \\
\hline Housewives & $127(34)$ & $243(66)$ & \\
\hline
\end{tabular}




\begin{tabular}{|c|c|c|c|}
\hline $\begin{array}{c}\text { Non regulated } \\
\text { profession* }\end{array}$ & $41(44)$ & $53(56)$ & \\
\cline { 1 - 2 } $\begin{array}{c}\text { Regulated } \\
\text { profession** }\end{array}$ & $8(14)$ & $50(86)$ & \\
\hline \multicolumn{3}{|c|}{ Fathers' Occupation } \\
\cline { 1 - 2 } Student /pupil & $9(50)$ & $9(50)$ & \multirow{2}{*}{0.007} \\
\cline { 1 - 3 } Unemployed & $11(44)$ & $14(56)$ & \multirow{2}{*}{$215(63)$} \\
\cline { 1 - 1 } $\begin{array}{c}\text { Non regulated } \\
\text { profession }\end{array}$ & $125(37)$ & $120(74)$ & \\
\hline $\begin{array}{c}\text { Regulated } \\
\text { profession }\end{array}$ & $37(26)$ & \\
\hline
\end{tabular}

* Any profession exercised on the basis of well-defined qualifications, by an individual, independently and under the person's own responsibility [15].

** Professions exercised under the responsibility of a third party. Referring to civil servants in our study [15]

Table 6: Relationship between health education and maternal practices.

\begin{tabular}{|c|c|c|c|}
\hline & Poor practicesn (\%) & Good practicesn (\%) & P-value \\
\hline \multicolumn{4}{|c|}{ Health education } \\
\cline { 1 - 3 } Not receive & $101(43)$ & $132(57)$ & 0.000 \\
\hline Received & $81(26)$ & $226(74)$ & \\
\hline
\end{tabular}

Table 7: Relationship between the mothers and their environmental practices.

\begin{tabular}{|c|c|c|c|}
\hline & Poor practices n (\%) & $\begin{array}{c}\text { Good practices n } \\
\text { (\%) }\end{array}$ & P-value \\
\hline \multicolumn{4}{|c|}{ House hold environment } \\
\cline { 1 - 3 } Unfavorable & $91(40)$ & $139(60)$ & \multirow{2}{*}{0.013} \\
\hline Favorable & $91(29)$ & $219(71)$ & \\
\hline
\end{tabular}

\section{Discussion}

Most of the mothers in our study were in the 15-25 years age group, similar to the 2011 Demographic Health Survey where most of the women surveyed were in the 15 - 19 years age group [4]. In addition, early marriages, which are frequent in the area, lowers the overall age of procreation. We noted that $40.4 \%$ of mothers had had secondary education, and $23.7 \%$ were not educated. These are contrary to the results of the survey on early childhood development in the Adamawa region done in 2007 in which $51 \%$ of the mothers were not educated [9]. This difference could be due to the fact that the survey took into account the urban and rural areas.

In our study, the majority of mothers $(76.1 \%)$ had adequate knowledge on diarrhea, notably the definition, causes, prevention and signs that should motivate consultation. These results could be explained by the fact that community Integrated management of Childhood Illnesses was introduced in the Adamawa region, with the aim of reducing childhood mortality through education of families on the knowledge and management of common childhood illnesses in children at home including diarrhea. Amare et al. [10] in
Ethiopia had similar results with $63.6 \%$ of mothers who had a good knowledge of diarrhea [10]. We observed a statistically significant relationship between the mothers' knowledge, their educational level and their professions. The knowledge of the mothers was much better when they had a good educational level and when they were civil servants. In fact, educated mothers have more access to the public service, and they understand better the information given on diarrhea, thus improving their knowledge. Similar findings were noted in Iran [7, 8], Ethiopia [10], and Gambia [11].

We observed a statistically significant relationship between the knowledge of the mothers, fathers' level of education and their profession. The mother's knowledge was better when the father was educated and working in the public service. The educational level of the father would permit better integration of the information received, so consequently the educated father would better train the mother. In Iran, Ghasemi et al. [7] had the same relationship. We also noted that there was a statistically significant relationship between the knowledge of the mothers and receiving health education on diarrhea. This shows that health education of the mothers is a good means of information on diarrhea.

We had a statistically significant relationship between the knowledge of mothers and the household environment. Mothers who had tap water as source of water supply and who had latrines had better knowledge than those who did not have. This could be explained by the fact that these households would likely be of a higher socio-economic status and therefore have easier access to the various sources of information on diarrhea. We observed that $66.3 \%$ of the mothers had good practices towards diarrhea, with the use of oral rehydration therapy, feeding during diarrhea, and consultation at a health facility. Given that the level of knowledge was high in our study, it could explain the good practices that the mothers had towards diarrhea. In Ethiopia 45.9\% of mothers had good practices in 2014 [10] against $2.3 \%$ in 1991 [12] towards diarrhea.

We had a statistically significant relationship between the level of education, profession of mother and practices towards diarrhea. Practices were best in mothers who were educated and were civil servants and these practices improved with the increase in the level of education. These results are similar to those of the Demographic Health Survey of 2004 in Cameroon, in which mothers with the secondary school level had the highest use of ORT [13]. Studies in Ethiopia [10], Nigeria [14] and Iran [7,8] observed similar findings. Indeed, educated mothers would easily understand and integrate the information received and this would influence the choice of treatment and hence improve their practices.

A statistically significant relationship was observed between the father's education, father's profession and practices of the mothers. The practices of the mothers improved with the father's educational level and also with fathers that were civil servants. This can be explained by the fact that educated fathers can easily 
read and assimilate information and so educate mothers about the management of children on diarrhea. Also the father as head of the family would take care of the family financially and would thus have a decision-making power in the management of childhood illnesses.

We found a statistically significant relationship between the practices of the mothers and receiving health education. Mothers who received health education had better practices. Mothers who have received health education would be informed about the attitude, and the choice of treatment. We had a statistically significant relationship between the mothers' environment and her practices. Mothers who lived in households that were using tap water and latrines had better practices. This can be explained by the fact that mothers living in a favorable environment were of a higher socioeconomic level and therefore have easier access to information with good knowledge and therefore good practices.

\section{Conclusion}

This study shows that most mothers from this urban area in the Northern part of Cameroon have sufficient knowledge on diarrhea as well as good practices towards the home management of diarrhea. These are influenced by the level of education of both parents, health education and by the environment the family lives in. To sustain this knowledge and good practices key health messages should be given to all mothers on diarrhea prevention and home management. Zinc and oral rehydration salts should be made available at all times in all health facilities. Moreover, the community component of IMCI should be reinforced in that region.

\section{Acknowledgement}

We want to thank all the parents who accepted to participate in this study and all the field workers who participated actively in the survey

\section{References}

1. WHO. Diarrhoea: why children are still dying and what can be done.

2. Bryce J, Boschi-Pinto C, Shibuya K, Black RE (2005) WHO Child Health Epidemiology Reference Group. WHO estimates of the causes of death in children. Lancet 365 (9465): 1147-52.
3. OMS/UNICEF (2001) Prise en charge de la diarrhée aïgue. Rapport d'une réunion d'experts organisée conjointement par l'UNICEF et l'OMS. New York, USA.

4. Institut Nationale de la Statistique (2011) Enquête Démographique et de Santé et à Indicateurs Multiples EDS-MICS 2011, Cameroun, p. 18-9.

5. Délégation régionale de la santé de l'Adamaoua. Répartition des populations de la ville de Ngaoundéré (2015) Rapport réactualisé du district de la Vina. Ngaoundéré : District de santé de la Région de l'Adamaoua.

6. Davis F, Drucker J, Moren A (2010) Aspects particuliers de la pratique de l'épidémiologie. ISPED 2e: 2-4.

7. Ghasemi AA, Telebian A, Alani NM, Mousavi GA (2013) Knowledge of mothers in management of diarrhea in under-five children, in Kashan, Iran. Nurs Midwifery Studs 1(3): 158-62.

8. Khalili M, Mirshahi M, Zarghami A, Rajabria M, Farahmand F (2013) Maternal knowledge and practice regarding children diarrhea and diet in Zehedan, Iran. Health Scope (1): 19-24.

9. Institut Nationale de la Statistique du Cameroun, MINEPAT (2007) Enquête Finale sur le développement du jeune enfant dans la province de l'Adamaoua.

10. Amare D, Dereje B, Kassie B, Tessema M, Mullu G, Alene B, et al. (2014) Maternal knowledge and practice towards diarrhea management in under five children in Fenote Salam town west zone Amhara regional state North West Ethiopia. J infect Dis 2 (6): 182.

11. Sillah F, Ho HJ, Chao JC (2013) The use of oral rehydration salt in management of children under five old with diarrhea in the Gambia, knowledge, attitude and practice. Nutrition 11(12): 1368-1373.

12. Ketsela T, Asfaw M, Belachew C (1991) Knowledge and practice of mother/ care takers toward diarrhea and it treatment in rural communities in Ethiopia. Ethiopia Med J 29 (4) :213-224.

13. Enquête Démographique et de Santé et à Indicateurs Multiples EDS (2004) République du Cameroun : Institut Nationale de la Statistique pp. 159-63.

14. Jamiu MO, Odile UV, Abu Saeed K, Abu-Saeed MB (2012) Assessment of mothers' knowledge of home management of childhood diarrhea in a Nigerian setting. Int J Pharm Res Bio Sci 1 (4) : 168-184.

15. Profession libérale [Internet]. Wikipédia. 2015.

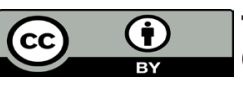
This work is licensed under Creative Commons Attribution 4.0 License
DOI: $10.32474 /$ PAPN.2018.01.000112

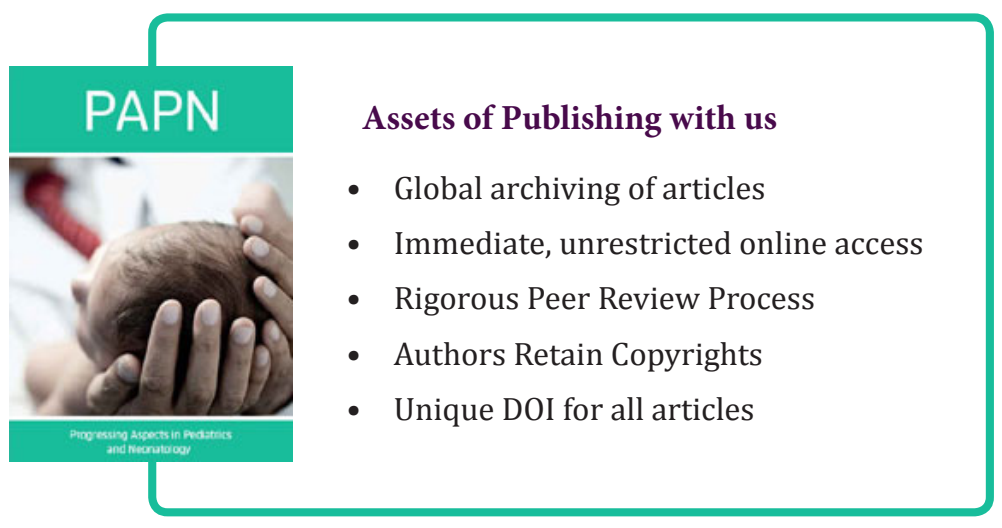

